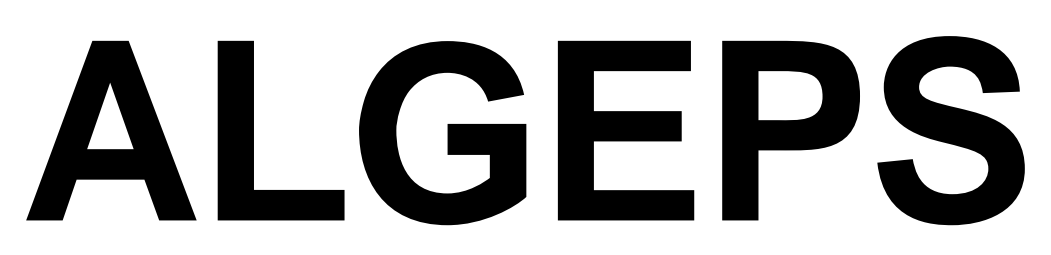

REVISTA DE GEOLOGIA, SĖRIE B no 592 - Juny del 2012

RECORRIDO DESDE L'AINSA A ESCALONA, A ESCUAIN, A BIELSA Y AL VALLE DE PINETA, A TRAVÉS DEL PATRIMONIO GEOLÓGICO Y MINERO DE LA COMARCA DEL SOBRARBE

Josep M. Mata-Perelló 


\section{RECORRIDO DESDE L'AINSA A ESCALONA, A ESCUAÍN, A BIELSA Y AL VALLE DE PINETA, A TRAVÉS DEL PATRIMONIO GEOLÓGICO Y MINERO DE LA COMARCA DEL SOBRARBE}

\section{ADVERTENCIAS PREVIAS}

Como en otros recorridos de RECONOCIMIENTO GEOLÓGICO (o de RECONOCIMIENTO GEOLÓGICO Y MINERO), el recorrido se compondrá de diversas PARADAS.

Por otra parte, habrá que tener en cuenta, en todo momento, (especialmente antes de empezar los recorridos de los diferentes tramos), el estado de los caminos y carreteras, por donde transitará el recorrido.

Finalmente, como ya hacemos en otros recorridos similares, queremos decir que hace falta tener un cuidado muy especial en el respeto a la naturaleza, a lo largo de todo el recorrido del itinerario, y también fuera de él.

\section{BREVE INTRODUCCIÓN GEOLÓGICA}

Todo el recorrido de este itinerario, se desarrollará por distintas zonas ocupadas por el Sistema Pirenaico (o simplemente por los Pirineos). Concretamente, en todo el recorrido se circulará por el denominado Surpirineo Central.

Así, el recorrido se iniciará en las cercanías de l’Ainsa, dentro del denominado Surpirineo Central, por los denominados Pirineos Meridionales (también a menudo conocidos como Prepirineo Meridional).

Así, se irá circulando desde l'Ainsa hasta Escalona, Escuaín (haciendo una hijuela). Luego a Bielsa y posteriormente al Valle de Pineta.

\section{BREVE INTRODUCCIÓN GEOGRÁFICA}

El recorrido del presente itinerario se efectuará exclusivamente por una comarca aragonesa, por la del Sobrarbe. Así el recorrido se iniciará en la población de l'Ainsa, recorriendo la comarca hasta llegar al Valle de Pineta.

Por otro lado, la totalidad del recorrido transitará por la cuenca del río Cinca, desde l’Ainsa hasta prácticamente el nacimiento del río en el Valle de Pineta. Aún así, 
un pequeño tramo del recorrido, se efectuará por uno de sus afluentes, concretamente por el río Yaga, por los alrededores de Escuaín.

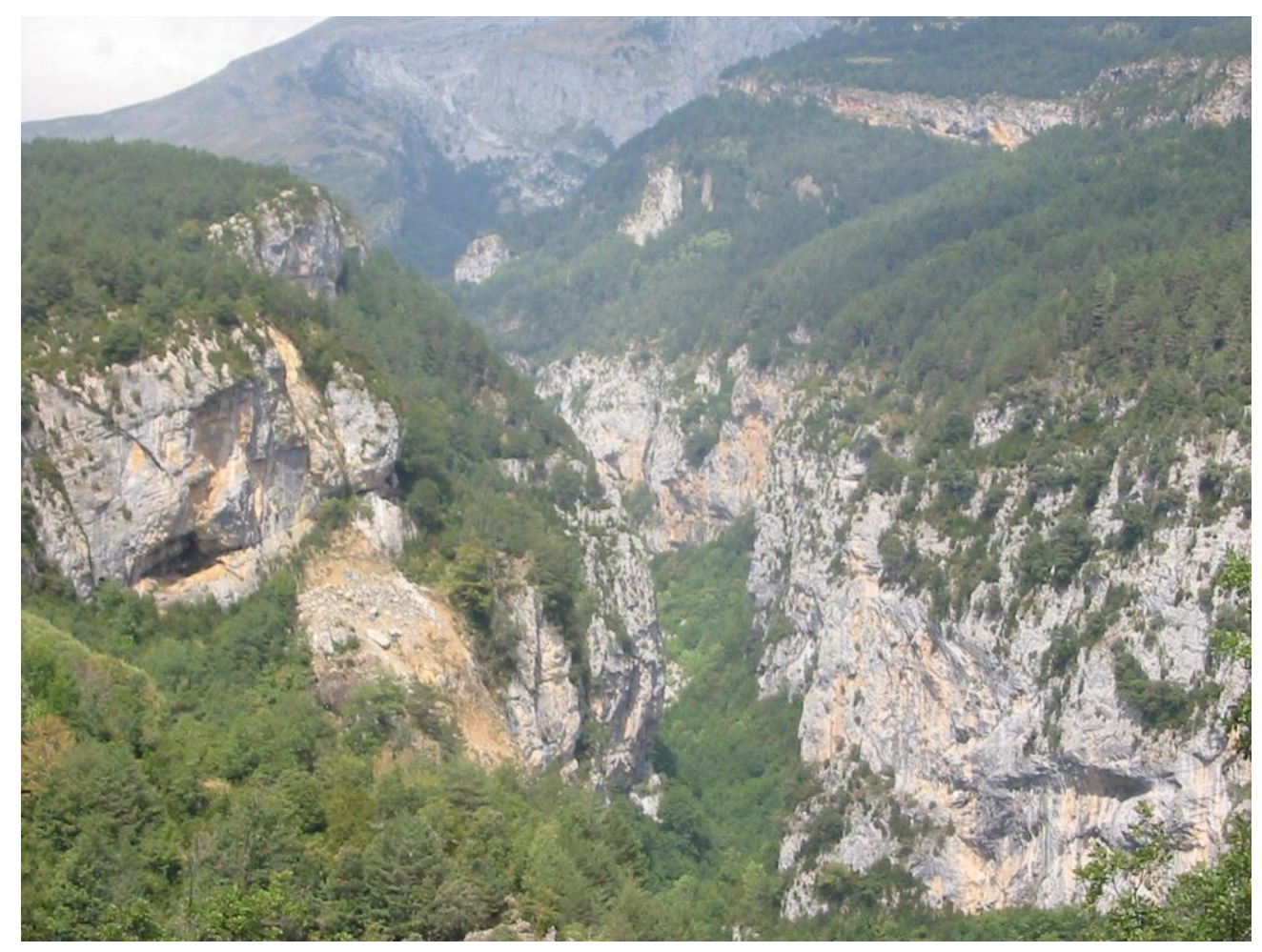

El Congosto o cañón de Escuaín

\section{OBJETIVOS GENERALES DE ESTE ITINERARIO}

En este itinerario, los objetivos generales que se han de conseguir, se pueden concretar en los siguientes aspectos:

1.- Estudio y reconocimiento de los materiales mesozoicos y cenozoicos situados en el Surpirineo Central. Estos materiales los iremos encontrando a lo largo de casi todo el recorrido del itinerario.

2.- Estudio y reconocimiento de las estructuras del Surpirineo Central, a lo largo de todo el recorrido del itinerario.

3.- Observación y estudio de los materiales mesozoicos (fundamentalmente del Triásico Superior; y en menor grado del Jurásico y del Cretácico), que constituyen los relieves de las zonas septentrionales del Manto del Cotiella, por donde se transitará por las inmediaciones de Salinas de Sin.

4.- Observación y estudio de los materiales mesozoicos (fundamentalmente del Triásico Superior; y en menor grado del Cretácico), que constituyen los relieves del Manto de Gavarnie, por donde se transitará entre las inmediaciones de Salinas de Sin y las de Bielsa; así como entre esta población y las inmediaciones del Parador Nacional del Monte Perdido. 
5.- Visión de algunas de las antiguas explotaciones mineras encontradas a lo largo del recorrido del itinerario.

6.- Visión de los diferentes lugares directamente relacionados con el Patrimonio Geológico que iremos encontrando a lo largo del recorrido de este itinerario. Dentro de este contexto, cabe mencionar el Congosto (o Cañón) de Escuaín y el Valle de Pineta.

7.- Visión de los diferentes lugares directamente relacionados con el Patrimonio Minero que veremos a lo largo del recorrido de este itinerario.

\section{ANTECEDENTES BIBLIOGRÁFICOS}

En relación con este itinerario, no conocemos ningún antecedente, de otro autor relativo a otro itinerario que discurra por este lugar. Nosotros hemos escrito un itinerario que discurre parcialmente por estos lugares: MATA-PERELLÓ (2007). Así pues, en cierto sentido el que ahora presentamos es una primicia.

Por otra parte, haremos mención de algunos trabajos, de carácter geológico generalista, que corresponden a los trabajos del IGME (1972, 1974 y 1975), relativos al Mapa Geológico de España (a Escala 1.200.000), al Mapa Metalogenético de España y al Mapa de Rocas Industriales de España.

Con respecto a las mineralizaciones que iremos encontrando, mencionaremos los trabajos de: CALVO et altri (1988); MAESTRE (1845); así como nuestros trabajos: MATA-PERELLÓ (1987 y 1992).

También mencionaremos el trabajo de PRAMES (2005) dedicado a la comarca del Sobrarbe. Así como el del GOBIERNO DE ARAGÓN (2001), dedicado a los Puntos de Interés Geológico de Aragón.

Finalmente, diremos que todos estos trabajos (así como otros que ahora no hemos aludido), figurarán mencionados, por orden alfabético, en el apartado dedicado a las REFERENCIAS BIBLIOGRÁFICAS.

\section{RECORRIDO DEL ITINERARIO}

Este recorrido se iniciará en las inmediaciones de la población de l'Ainsa, desde donde se dirigirá hacía el Norte, por la carretera autonómica A-138. Por ella, pronto llegaremos a Labuerda, en donde se realizará la primera parada. Luego, el recorrido se dirigirá hacía Escalona. A partir de ahí, se iniciará una hijuela, yendo hacía Puertotas y hacía Escuaín. En este tramo se realizaran diversas paradas. Tras ello, el recorrido retornará a Escalona, para continuar el camino hacía el Norte. Tras sobrepasar el Mesón de Puértolas, se realizará una nueva parada junto a la carretera. Después el recorrido atravesará el Paso de las Devotas, en donde se realizará una nueva parada. Tras ello, el recorrido seguirá hacia Salinas de Bielsa (y Salinas de Sin), desde donde se continuará 
hacía Bielsa. A partir de este pueblo se dejará la carretera A-138, para continuar por la carretera local que se dirige a Javierre, continuando hacía las inmediaciones de la Espierba y llegando al final de la carretera. En este sector, dentro del Valle de Pineta, se efectuará una nueva parada, la última del recorrido de este itinerario.

\section{DESCRIPCIÓN DEL ITINERARIO}

Como de costumbre, haremos una serio de PARADAS (o ESTACIONES), en donde se realizaran diversas explicaciones en torno a las características del lugar en donde se halla la PARADA. Por otra parte, en ellas haremos mención del término municipal dónde se encuentran, así como del número del "Mapa Topográfico Nacional (a escala 1:50.000, que indicaremos entre paréntesis. Así, ahora (en este recorrido) utilizaremos solamente las hojas: 146 (o de Bujaruelo), 178 (de Broto), 179 (de Bielsa) y 211 (o de Boltaña). Así, la relación ordenada de las paradas que constituyen el recorrido de este itinerario, es la siguiente:

PARADA 1. PLANTA DE ÁRIDOS DE LABUERDA, (término municipal de Labuerda, comarca del Sobrarbe). (Hoja 211).

El recorrido del presente itinerario, cabe iniciarlo en la población de 1'Ainsa. Desde ahí, nos convendrá tomar la carretera autonómica A-138, hacía el Norte, hacía Bielsa. Bien pronto, a unos 3’5 Km, llegaremos a la Planta de Áridos de Labuerda. Ahí efectuaremos la primera parada de este itinerario.

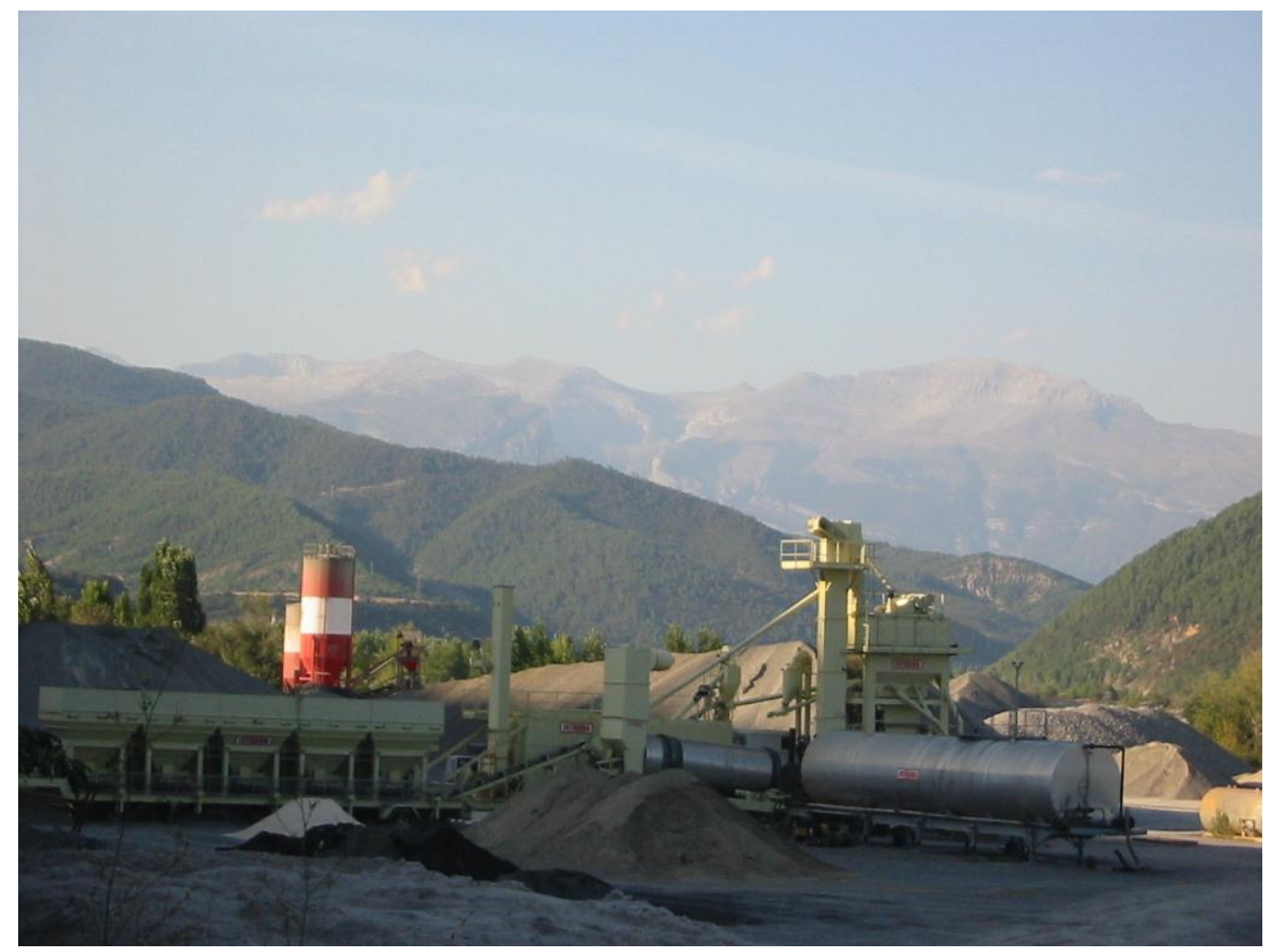

Planta de áridos de Labuerda 
En este recorrido, habremos ido encontrando materiales cenozoicos, formando parte de los afloramientos del Pirineo Meridional. En su mayor parte, estos materiales tienen carácter turbidítico.

Por otra parte, en el lugar de la parada hay una planta de áridos. En ella se tratan los materiales cuaternarios extraídos de diversas graveras

\section{PARADA 2. EL CASTILLO MAYOR DESDE LA COLLADA CUSTODIA, (término municipal de Puértolas, comarca del Sobrarbe). (Hoja 178).}

Después de realizar la parada anterior, cabe llegar hasta la población cercana de Labuerda, con la intención de seguir luego por la carretera A-138 hacía Escalona. A la salida de la misma conviene tomar la carretera local de Fanlo, por la izquierda. Pero casi inmediatamente hay que tomar (por la derecha) la carretera de Escuaín. Por esta carretera local, pasaremos primero por Belsierre y después llegaremos a la población de Puértolas, en cuyas inmediaciones efectuaremos una nueva parada, a unos $13 \mathrm{Km}$ de la primera parada, concretamente a $2 \mathrm{Km}$ del pueblo, en la Collada Custodia, yendo hacía Escuaín.

En este recorrido iremos encontrando afloramientos de los materiales mencionados anteriormente, situados dentro de los Pirineos Meridionales en donde nos encontramos ahora situados.

Desde este lugar, mirando hacía el Norte, es posible ver las estructuras del monte de Castillo Mayor. Ahí puede verse un gran sinclinal, formando parte de la escama de cabalgamiento de Castillo Mayor.

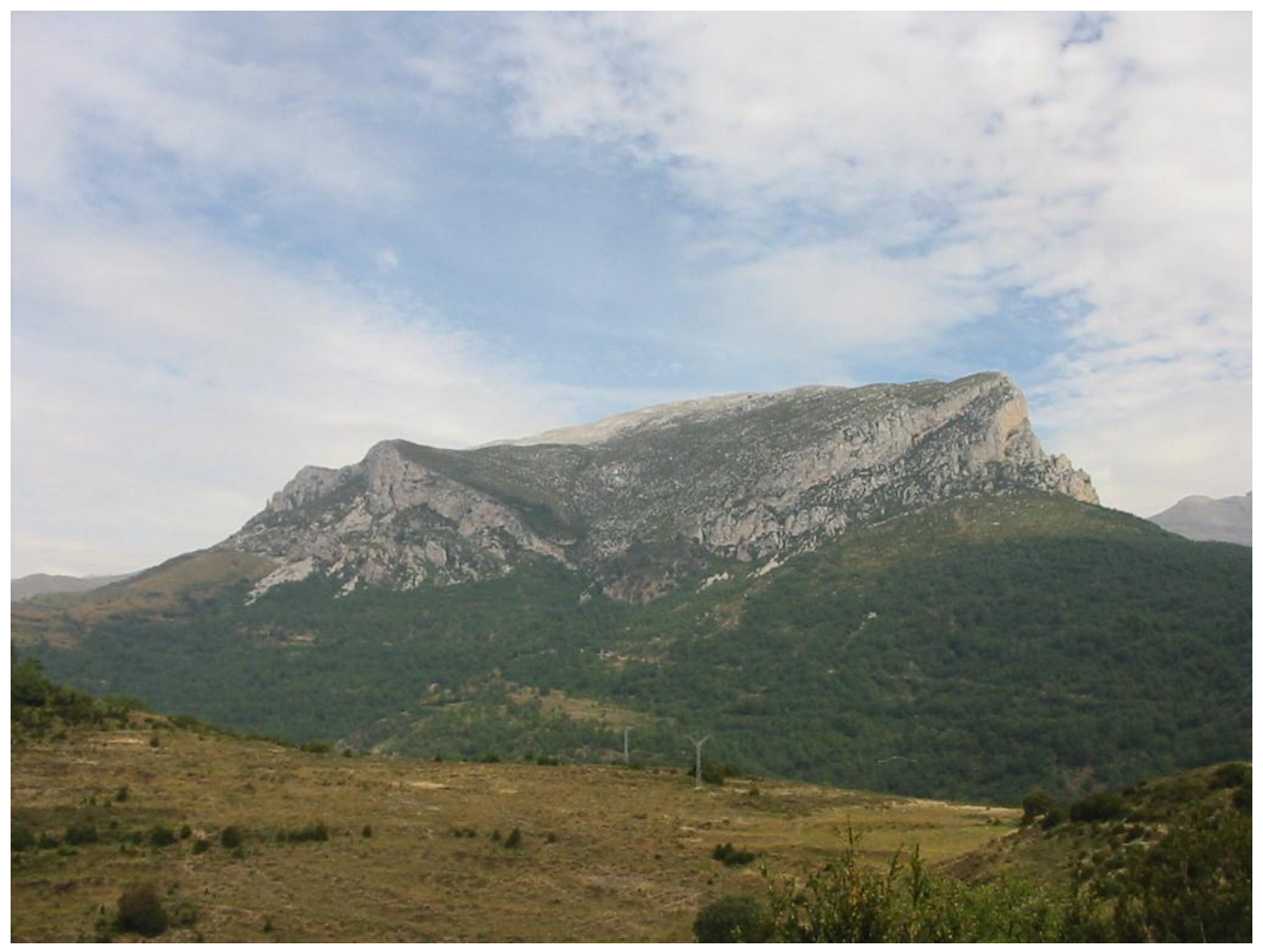

El Sinclinal de Castillo Mayor 
PARADA 3. CAÑÓN DE ESCUAÍN, (Escuaín, término municipal de Puertotas, comarca del Sobrarbe). (Hoja 178).

Desde la parada anterior, es necesario continuar por el recorrido de la carretera que conduce a Escuaín. Al llegar ahí, será necesario hacer un pequeño recorrido a pie, con la intención de llegar al borde del cañón. Ahí realizaremos una nueva parada, a unos $5 \mathrm{Km}$ más allá de la anterior, compatibilizando unos 200 metros hechos a pie.

El recorrido desde la parada anterior, lo habremos realizado en parte bordeando el monte del Castillo Mayor, que hemos visto en la parada anterior. Este monte, de naturaleza eminentemente carbonatada ha dado lugar a diversos depósitos de piedemonte, que han sido explotados en diversos lugares, a lo largo de todo este recorrido.

Estas rocas carbonatadas son las que también afloran entorno a Escuaín, y en el camino de acceso al borde del cañón, que habremos realizado a pie. Desde este lugar, por otra parte, puede verse una magnífica perspectiva de este cañón, abierto por el río Yaga, al atravesar los materiales carbonatados.

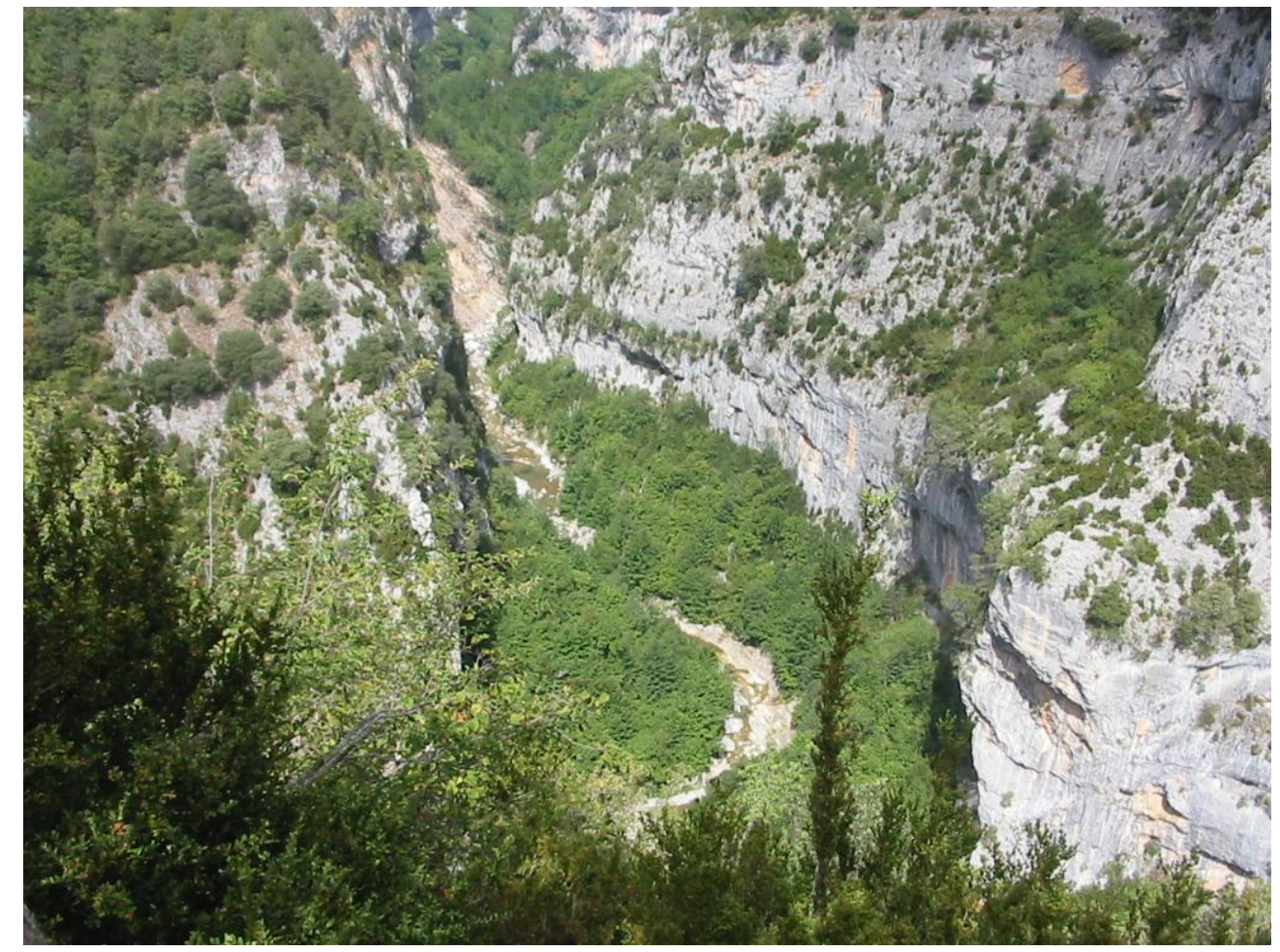

Un aspecto del Cañón de Escuaín

PARADA 4. HORNO DE CAL, (el Mesón de Puertotas, término municipal de Puertotas, comarca del Sobrarbe). (Hoja 179).

Tras realizar la parada anterior, conviene retornar hacia las inmediaciones de Escalona, terminando así la hijuela que nos ha llevado a Puértolas y a Escuaín. Así, ahora volveremos a continuar hacía el Norte siguiendo por la carretera autonómica A-139. A unos 3’5 Km de Escalona encontraremos el Mesón de Puértolas, y poco después un horno 
de cal, situado a la izquierda de la carretera. Ahí efectuaremos una nueva parada, a unos 4 $\mathrm{Km}$ de Escalona y a unos $20 \mathrm{Km}$ de la parada anterior.

En este recorrido habremos encontrado de nuevo los materiales cenozoicos y mesozoicos que forman parte del Pirineo Meridional, en donde continuamos estado situados, desde el principio del recorrido.

En este lugar había unas antiguas explotaciones (más bien pequeñas) de los materiales carbonatados. Estos fueron utilizados en un horno de cal, medio destrozado, situado junto a la carretera.

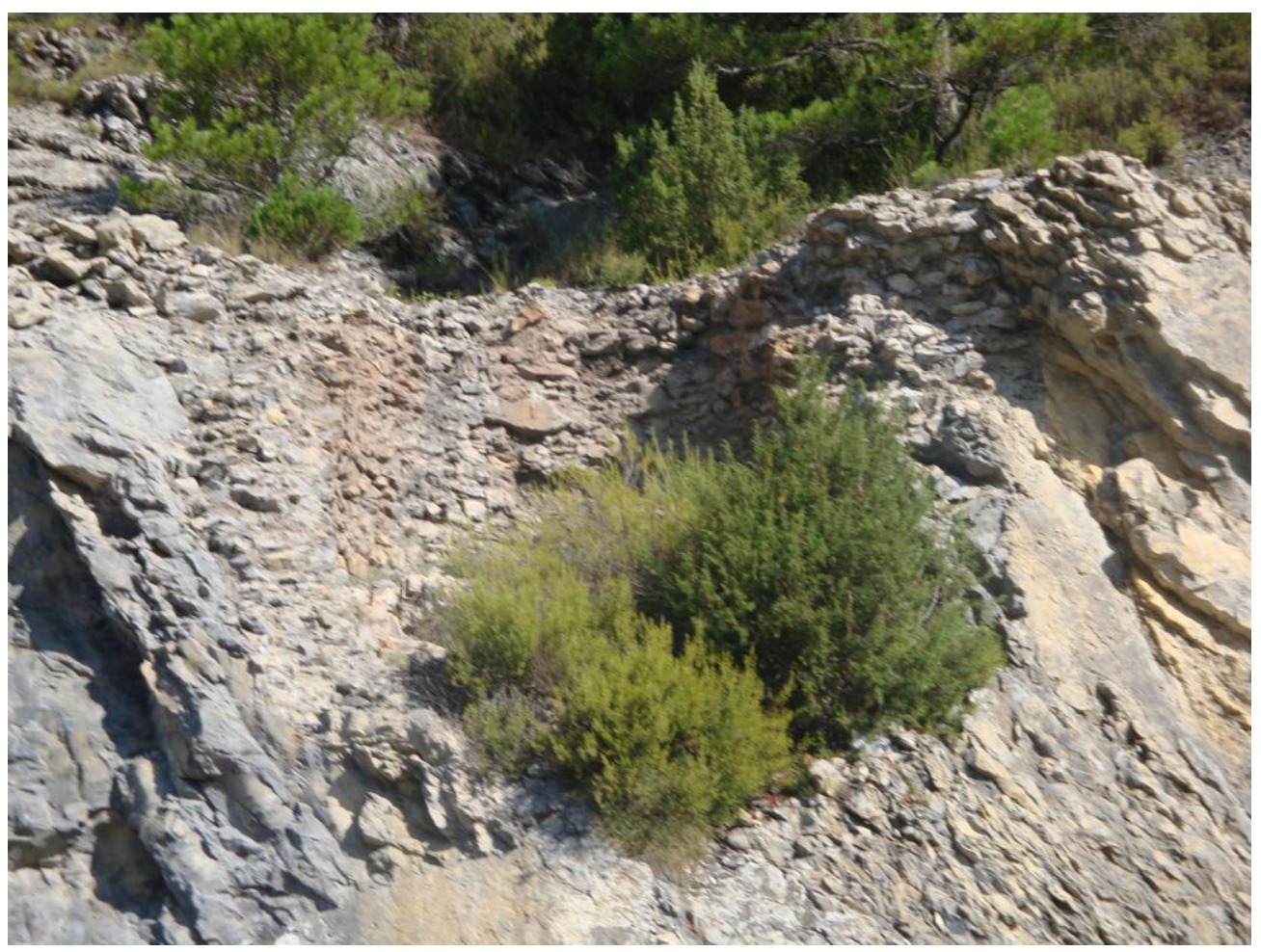

Restos de la parte alta del horno

PARADA 5. EL PASO DE LAS DEVOTAS, (Lafortunada, término municipal de Tella - Sin, comarca del Sobrarbe). (Hoja 179).

Después de realizar la parada anterior, es necesario continuar por la carretera A139, la cual conduce primero hacía el Hospital de Tella y posteriormente a Lafortunada, dejando antes por la derecha el ramal que conduce a Tella. Mas adelante, la carretera circula junto a un congosto del río Cinca. A la salida del mismo efectuaremos una nueva parada, a unos $14 \mathrm{Km}$ de la parada anterior.

En este recorrido habremos ido cortando afloramientos de los materiales cenozoicos (y también de los mesozoicos), eminentemente carbonatados, que forman parte del Pirineo Meridional, en donde ahora nos encontramos situados, dentro del Manto de Cotiella. En cualquier caso, tras sobrepasar Lafortunada (a unos 1'5 Km) habremos entrado en un estrecho desfiladero: el Paso de las Devotas, en recuerdo de unas monjas que perecieron al querer pasar por él camino que lo seguía, en medio de un temporal. Se 
trata de un cañón abierto por el río Cinca al atravesar los materiales carbonatados, de los que hemos hablado anteriormente.

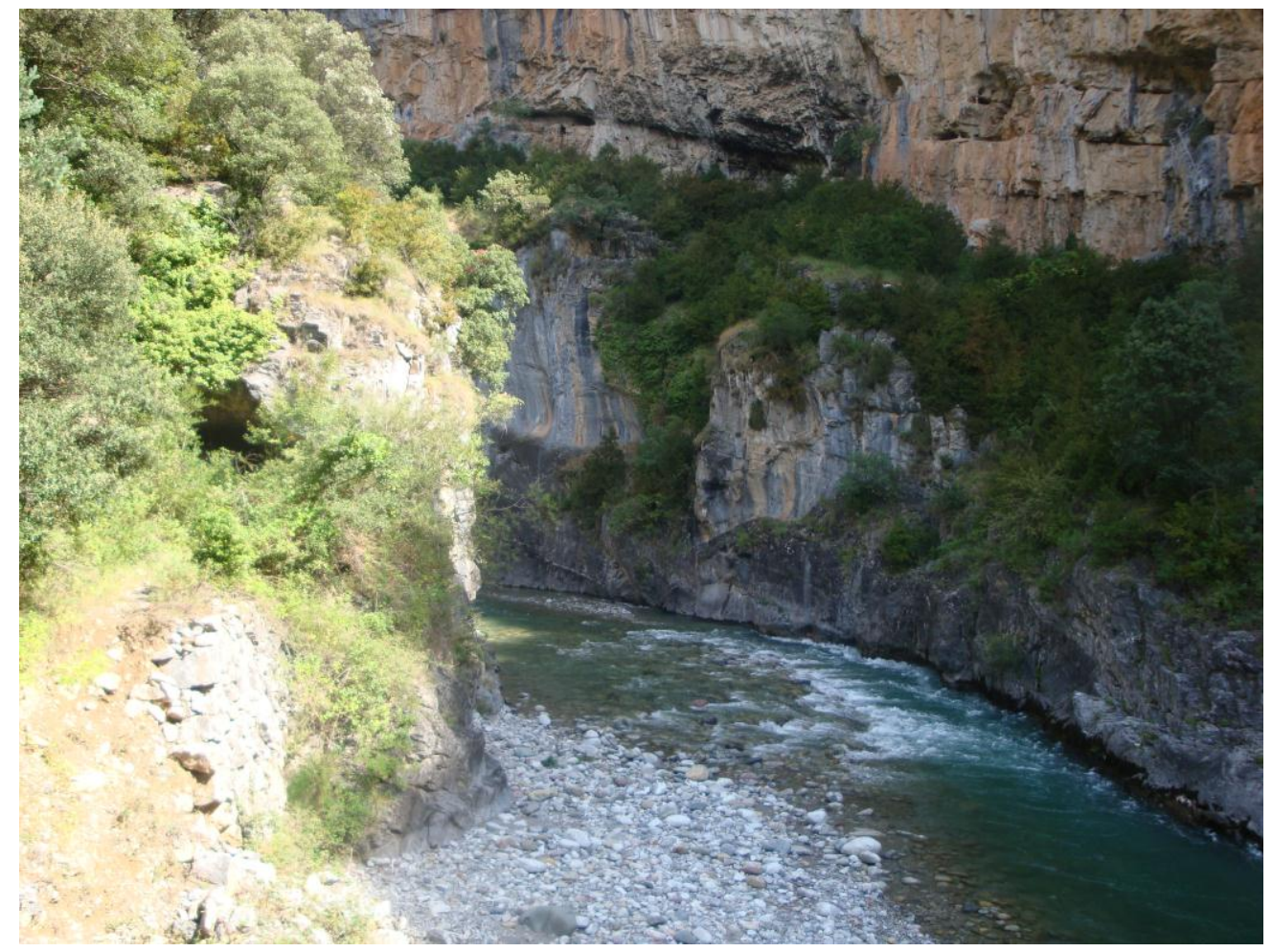

Un aspecto del congosto en sus sectores más meridionales

PARADA 6. LA FARGA DE BIELSA, (término municipal de Bielsa, comarca del Sobrarbe). (Hoja 179).

Tras realizar la parada anterior, será necesario continuar por la carretera autonómica A-138c, que conduce hacía el Norte. Así, pronto se llegará a Salinas (Salinas de Sin y Salinas de Bielsa), de donde parte la carretera al Valle de Gistaín (o Chistau), siguiendo el río Cinqueta. Nosotros seguiremos hacía el Norte, con la intención de llegar a Bielsa. Al llegar ahí, tras cruzar el centro del pueblo, iremos al paraje en donde estaba la Farga de Bielsa. Ahí haremos una nueva parada, a unos $10 \mathrm{Km}$ de la anterior parada.

Como en los casos anteriores, en este recorrido habremos ido encontrando afloramientos de los materiales cenozoicos y mesozoicos que forman parte del Pirineo Meridional. Estos son los materiales que se sitúan entorno al lugar en donde haremos la presente parada.

En este lugar había una antigua farga (la Farga de Bielsa, de la que apenas quedan algunas paredes cubiertas de vegetación y los canalillos por donde llegaba el agua para el funcionamiento de la farga. En este lugar se trataban los minerales de hierro explotados en el paraje de Mener, aguas arriba de Bielsa y de Parzán. Cabe considerar que gozó de una gran importancia durante los siglos XVII y XVIII. 


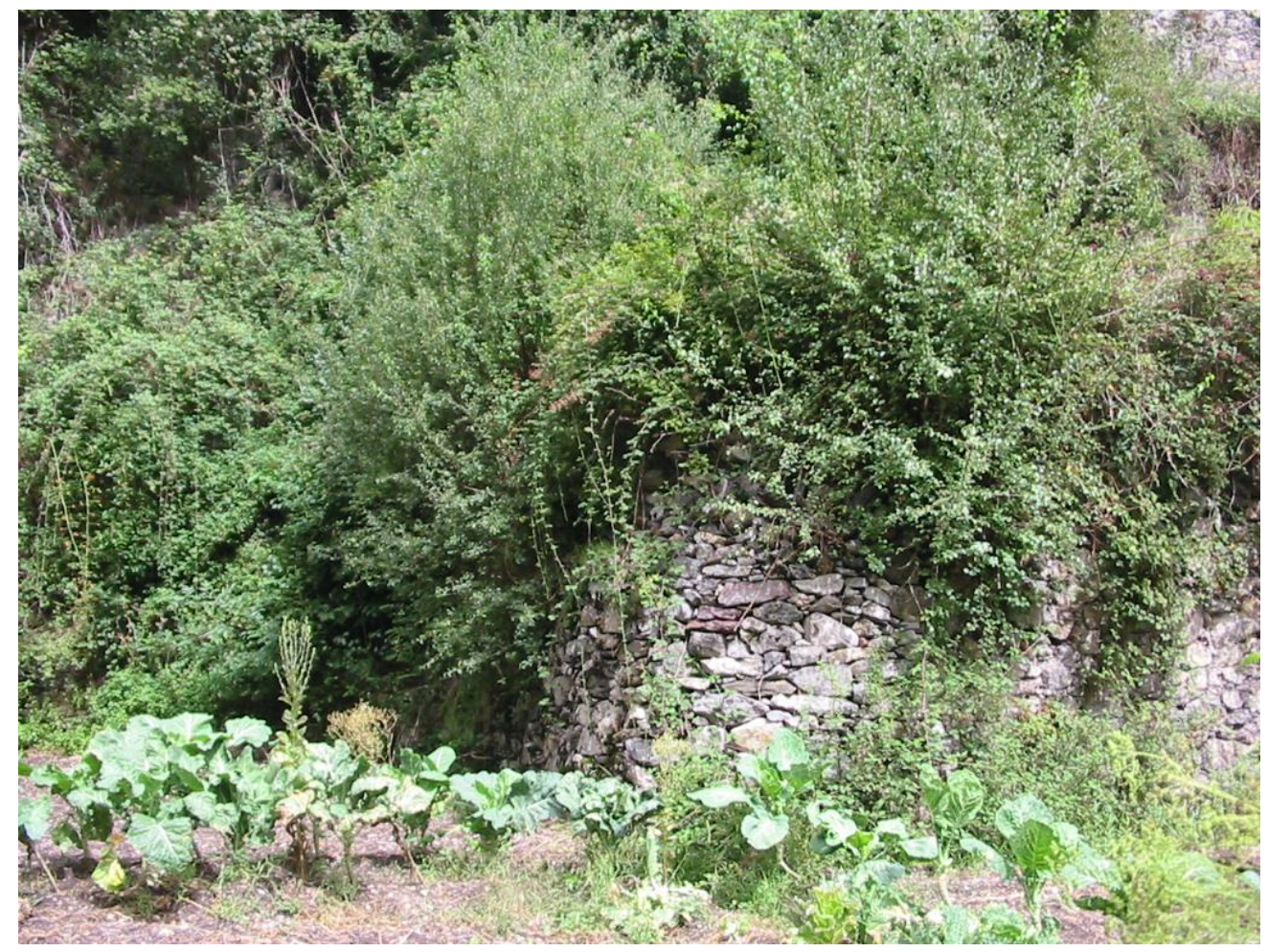

Restos de la Farga de Bielsa

PARADA 7. VALLE DE PINETA, (la Espierba, término municipal de Bielsa, comarca del Sobrarbe). (Hoja 179).

Tras realizar la parada anterior, conviene continuar por la carretera local (la HU-V6402) que desde Bielsa conduce al Valle de Pineta, remontando siempre el río Cinca. Por esta carretera pronto pasaremos por Javierre. Luego, la carretera pasará por las cercanías de la Espierba, y finalmente llegará al Parador Nacional del Monte Perdido. A partir de ahí iniciaremos un recorrido a pie, hasta las primeras cascadas del río Cinca. Por eso zona realizaremos una nueva parada, la última del presente recorrido, a unos $14-15 \mathrm{Km}$ de la anteriormente realizada.

En este recorrido, remontaremos inicialmente desde Bielsa hasta Javierre, el gran desnivel existente como consecuencia de la morfología glaciar. Luego, desde Javierre hasta el final de la carretera en el Parador, iremos ascendiendo suavemente por el majestuoso Valle de Pineta, entre afloramientos de los materiales cuaternarios que lo han ido configurando.

En el tramo final, de fuerte ascenso, hacía el denominado Balcón de Pineta, iremos encontrando afloramientos de los materiales mesozoicos (generalmente cabonatados) del Cretácico en su mayor parte. Estos materiales forman parte del Manto de Gavarnié.

Siguiendo el recorrido a pie, llegaremos a las cascadas del Cinca. Este río tras nacer en las inmediaciones del Circo de Pineta (otro precioso lugar), va descendiendo hasta llegar a las inmediaciones del mencionado Balcón de Pineta, desciende luego rápidamente hacía el Valle de Pineta, dando lugar a varias impresionantes y bellas cascadas. 


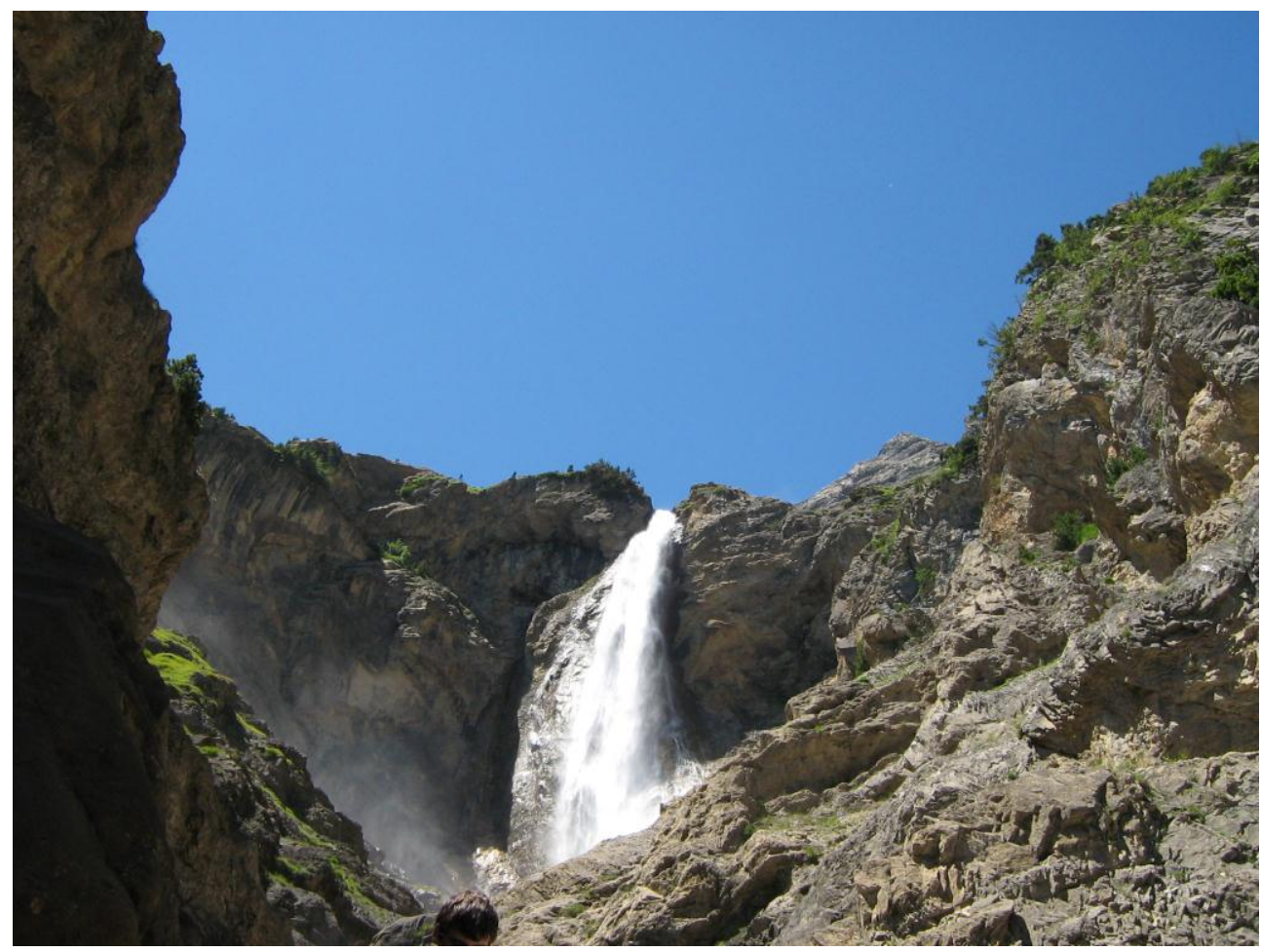

Una de las cascadas del Cinca

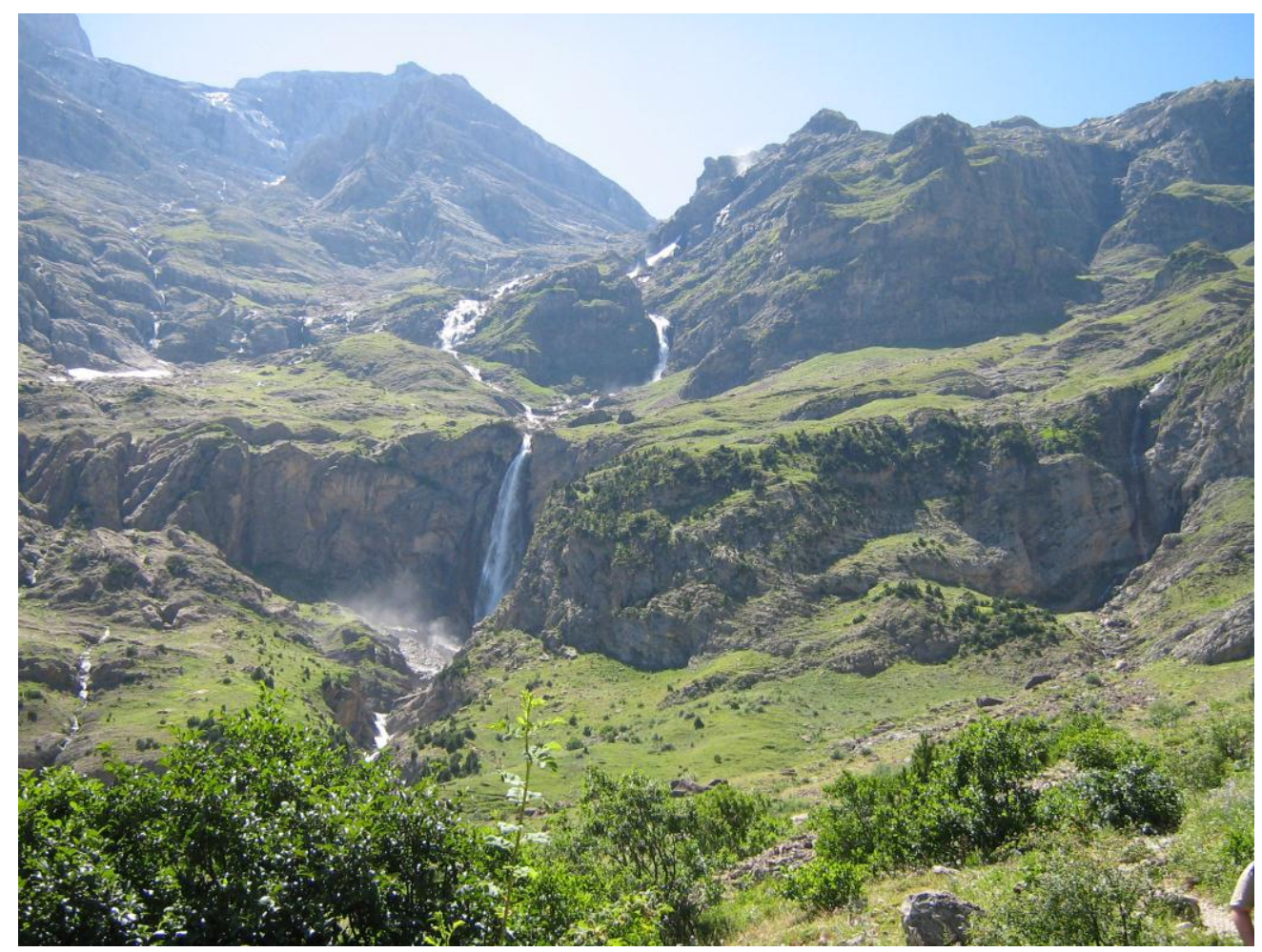

Un aspecto general del conjunto de las cascadas

Evidentemente, todo este conjunto: el Valle de Pineta, las Cascadas del Cinca, el Balcón de Pineta, el Circo de Pineta (englobados dentro del Parque Nacional del Valle de Ordesa - Monte Perdido) forman parte de nuestro Patrimonio Geológico 


\section{EN ESTE LUGAR FINALIZA EL ITINERARIO}

\section{BIBLIOGRAFÍA}

CALVO, M. et altri (1988). - Minerales de Aragón, Colección Temas Geológicos, 207 Pág. Zaragoza

GOBIERNO DE ARAGÓN (2001).- Puntos de Interés Geológico de Aragón. Consejería de Medio Ambiente del Gobierno de Aragón. Zaragoza

IGME (1972).- Mapa Geológico de España a escala 1:200.000 (Síntesis de la cartografía existente). Hoja y Memoria nº 23 (Huesca). Inst. Geol. Min. España

IGME (1973).- Mapa Metalogenético de España a escala 1:200.000. Hoja y Memoria $n^{\circ} .23$ (Huesca). Inst. Geol. Min. España

IGME (1975).- Mapa de Rocas Industriales de España a escala 1:200.000. Hoja y Memoria nº 23 (Huesca). Inst. Geol. Min. España

MAESTRE, A. (1845).- Descripción geognóstica del Distrito Minero de Cataluña y Aragón. Anales de Minas, t. III. Madrid

MATA - PERELLÓ, J.; (1987).- Introducción al conocimiento de las mineralizaciones aragonesas. Mineralogistes de Catalunya, t.III, pp. 258-265. Barcelona

MATA - PERELLÓ, J.M. (1992).- Inventario Mineralógico de la comarca del Sobrarbe. Rodeno, 13. 42 Pág. Manresa

MATA - PERELLÓ, J.M. (2007).- Itinerario geológico y mineralógico por la comarca del Alto Sobrarbe: desde Bielsa a Parzán y al Valle de Pineta. Recorrido por el patrimonio minero del Alto Sobrarbe. Inédito. 10 pag. Manresa

MATA - PERELLÓ, J.M. y SANZ-BALAGUË, J. (1992).- Guía de Identificación de Minerales, adaptada fundamentalmente a la Península Ibérica. Edic. Parcir, 243 pag. Manresa

PRAMES (2005).- Sobrarbe. Colección RUTASCAL por Aragón. Prames, Gobierno de Aragón. 119 pag. Zaragoza. 